\title{
A LATE EPISODE OF IRRADIATION IN THE EARLY SOLAR SYSTEM: EVIDENCE FROM EXTINCT ${ }^{36} \mathrm{Cl}$ AND ${ }^{26} \mathrm{Al}$ IN METEORITES
}

\author{
Weibiao Hsu \\ Laboratory for Astrochemistry and Planetary Sciences, Purple Mountain Observatory, Nanjing, 210008, China; wbxu@pmo.ac.cn \\ Yunbin Guan, L. A. Leshin, and Takayuki Ushikubo \\ Department of Geological Sciences, Arizona State University, Tempe, AZ 85287; \\ yunbin.guan@asu.edu, laurie.leshin@asu.edu, takayuki.ushikubo@asu.edu \\ AND \\ G. J. WASSERBURG \\ Lunatic Asylum, Division of Geological and Planetary Sciences, California Institute of Technology, \\ Pasadena, CA 91125; gjw@gps.caltech.edu \\ Received 2005 October 7; accepted 2005 November 22
}

\begin{abstract}
Late-formed halogen-rich phases in a refractory inclusion and a chondrule from the Allende meteorite exhibit large ${ }^{36} \mathrm{~S}$ excesses that linearly correlate with the chlorine concentration, providing strong evidence in support of the existence of the short-lived nuclide ${ }^{36} \mathrm{Cl}$ (mean life of $0.43 \mathrm{Myr}$ ) in the early solar system. The inferred ${ }^{36} \mathrm{Cl} /{ }^{35} \mathrm{Cl} \mathrm{ratios}$ at the time when these phases formed are very high $\left(\sim 4 \times 10^{-6}\right)$ and essentially the same for the inclusion and the chondrule and confirm the earlier report of ${ }^{36} \mathrm{~S}$ excess in another meteorite. In addition, the ${ }^{36} \mathrm{Cl}$ is decoupled from ${ }^{26} \mathrm{Al}$. The observed and any possible higher levels of ${ }^{36} \mathrm{Cl}$ cannot be the result of a supernova or AGB stellar source but require a late episode of energetic particle bombardment by the early Sun, in support of the arguments based on the previous discovery of ${ }^{10} \mathrm{Be}$. It is now clear that a blend of several sources is required to explain the short-lived nuclei when the solar system formed.
\end{abstract}

Subject heading: solar system: formation

\section{INTRODUCTION}

There is abundant evidence that short-lived radionuclides (mean lives ranging from $10^{5}$ to $10^{8} \mathrm{yr}$ ) that are now extinct were once present in the early solar system (ESS; see McKeegan \& Davis 2003). Evidence for these nuclides is found in minerals in meteorites that formed in the ESS and is recorded as excesses of the daughter nucleus that correlate with the abundances of a stable isotope of the parent element. The possible sources of the shortlived nuclides are a matter of great debate. Competing hypotheses include injection of freshly synthesized nuclides into the forming solar system from various nearby stars such as supernovae ( $\mathrm{SNe}$ ) or asymptotic giant branch (AGB) stars (see Wasserburg et al. 1994; Cameron et al. 1995; Sahijpal et al. 1998; Busso et al. 1999; Wasserburg et al. 2006, hereafter WBGN06). In addition, cogent arguments, both observational and theoretical, have been proposed that energetic particle irradiation by the active early Sun would produce many of these nuclei (Shu et al. 1997, 2001; McKeegan et al. 2000; Goswami et al. 2001; Feigelson et al. 2002; Leya et al. 2003; Desch et al. 2004). Both stellar injection and energetic particle irradiation mechanisms can produce ${ }^{26} \mathrm{Al}$ (mean life $\bar{\tau}=$ $1.03 \mathrm{Myr}),{ }^{41} \mathrm{Ca}(\bar{\tau}=0.15 \mathrm{Myr})$, and ${ }^{53} \mathrm{Mn}(\bar{\tau}=5.3 \mathrm{Myr})$ and in some cases can account for levels observed in primitive meteorites. However, the nuclide ${ }^{10} \mathrm{Be}(\bar{\tau}=2.3 \mathrm{Myr})$ cannot be produced in stars but requires spallation reactions either in the ESS (McKeegan et al. 2000; Goswami et al. 2001; Leya et al. 2003) or in the collapsing cloud (Desch et al. 2004). In contrast, ${ }^{60} \mathrm{Fe}$ $(\bar{\tau}=2.2 \mathrm{Myr})$ and ${ }^{107} \mathrm{Pd}(\bar{\tau}=9.4 \mathrm{Myr})$ require stellar sources (Busso et al. 1999; WBGN06). The short-lived nuclides thus provide vital information about the last nucleosynthetic injection event from nearby stars immediately before formation of the solar system and the intense solar activity of the early Sun. This research area involves diverse disciplinary approaches.
Among the short-lived nuclides, ${ }^{36} \mathrm{Cl}(\bar{\tau}=0.43 \mathrm{Myr})$ has received little attention. Chlorine is a volatile element and thus was not incorporated into primary high-temperature phases that make up unaltered $\mathrm{Ca}$,Al-rich inclusions (CAIs), where evidence for many short-lived nuclides has been found. ${ }^{36} \mathrm{Cl}$ has a major branched decay to ${ }^{36} \mathrm{Ar}\left(98.1 \%, \beta^{-}\right)$and a minor one to ${ }^{36} \mathrm{~S}$ $\left(1.9 \%, \epsilon\right.$ and $\beta^{+}$; Endt 1990). The search for ${ }^{36} \mathrm{Ar}$ excesses (the principal decay channel) has not led to any clear evidence in support of in situ decay of ${ }^{36} \mathrm{Cl}$ at high abundances. A few cases yielded hints of radiogenic ${ }^{36} \mathrm{Ar}$ excesses, implying ${ }^{36} \mathrm{Cl} /{ }^{35} \mathrm{Cl}$ in the ESS ranging from $1 \times 10^{-9}$ to $1.4 \times 10^{-6}$ (Villa et al. 1981 ; Jordan \& Pernicka 1981; Murty \& Wasserburg 1996; Murty et al. 1997). These are low levels, and interpretation of some of these data without a clear correlation with $\mathrm{Cl}$ is somewhat uncertain (Rai et al. 2003). Recent papers by Lin et al. (2004, 2005) reported a linear correlation of ${ }^{36} \mathrm{~S} /{ }^{34} \mathrm{~S}$ with ${ }^{35} \mathrm{Cl} /{ }^{34} \mathrm{~S}$ in late-formed halogen-rich alteration phases of a CAI. The inferred ${ }^{36} \mathrm{Cl} /{ }^{35} \mathrm{Cl}$ is very high $\left(\sim 5 \times 10^{-6}\right)$ and exceeds the range for an $\mathrm{AGB}$ or SN source if the delay between AGB injection and formation of the CAI and alteration is $\gtrsim 4 \times 10^{5} \mathrm{yr}$ (Busso et al. 1999; WBGN06). Furthermore, from consideration of Type II SN (SN II) yields, it can be seen that the short-lived nuclei ${ }^{26} \mathrm{Al},{ }^{36} \mathrm{Cl}$, etc., may only have negligible SN II contributions to the early solar system, if one takes into account the observed abundances of ${ }^{53} \mathrm{Mn}$ and ${ }^{60} \mathrm{Fe}$. The obvious conflicts between the earlier results and that of Lin et al. (2005) are not easily reconcilable. These workers attributed the source of the inferred ${ }^{36} \mathrm{Cl}$ to come from a supernova source. In addition, Lin et al. (2005) found essentially no ${ }^{26} \mathrm{Al}$ in the halogen-rich phases. If the ${ }^{36} \mathrm{Cl}$ was produced concurrently and earlier with the canonical solar value of ${ }^{26} \mathrm{Al} /{ }^{27} \mathrm{Al} \sim$ $5 \times 10^{-5}$, then it would imply a very high initial ${ }^{36} \mathrm{Cl} /{ }^{35} \mathrm{Cl}>10^{-3}$. This imposes a serious challenge to our current understanding of how ${ }^{36} \mathrm{Cl}$ and other short-lived nuclei were produced. There is an 


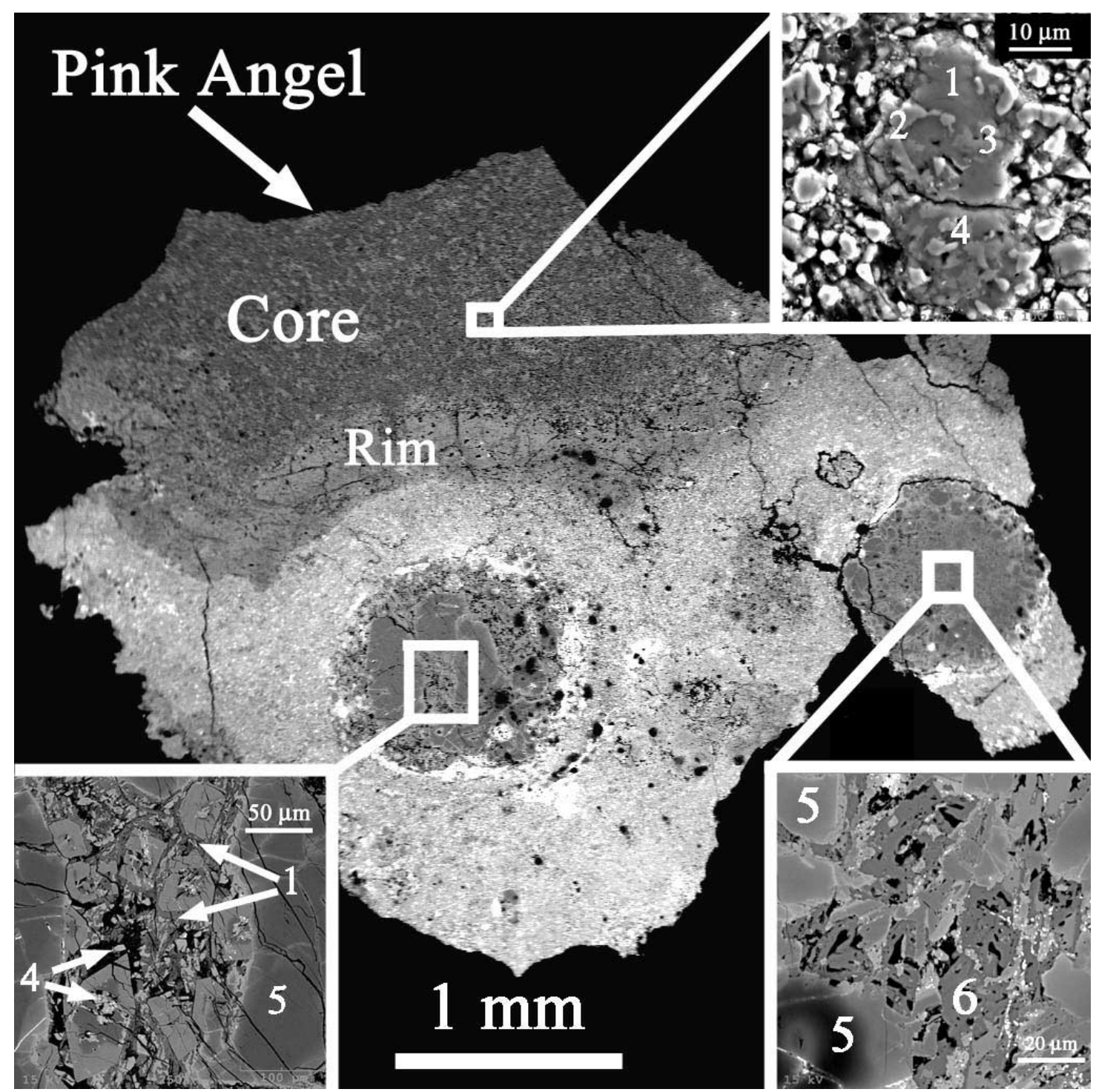

FIG. 1.-Backscattered electron images of the Pink Angel and two nearby porphyritic olivine chondrules. The top right inset is of a sodalite grain in the CAI core. Sodalite often contains small spinel, grossular, and diopside grains. The bottom left inset shows sodalite grains occurring interstitially between olivine grains of one chondrule. The bottom right inset shows euhedral to subeuhedral anorthite grains between olivine grains of the other chondrule. Mineral phases: (1) sodalite, (2) spinel, (3) grossular, (4) diopside, (5) olivine, and (6) anorthite.

urgent need for more complete and definitive measurements of the ${ }^{36} \mathrm{Cl}$ abundance to guide future work.

Here we present isotopic studies $(\mathrm{S}, \mathrm{Mg}$, and $\mathrm{O}$ ) of a Cl-rich inclusion in the Allende meteorite in an attempt to address the following questions: (1) Was ${ }^{36} \mathrm{Cl}$ widespread in the ESS and at what level? (2) How does ${ }^{36} \mathrm{Cl}$ correlate with other short-lived nuclides in the ESS? (3) What is the most plausible source of ${ }^{36} \mathrm{Cl}$ ? (4) Under what conditions did the secondary alteration of CAIs and chondrules occur?

\section{SAMPLE DETAILS AND EXPERIMENTAL APPROACH}

We have analyzed one altered CAI, named Pink Angel (Armstrong \& Wasserburg 1981), and a nearby porphyritic olivine chondrule from the Allende carbonaceous chondrite (Fig. 1). The Pink Angel has been studied earlier (Villa et al. 1981) for ${ }^{26} \mathrm{Al}$, ${ }^{129} \mathrm{I}$, and ${ }^{36} \mathrm{Cl}$ using ${ }^{36} \mathrm{Ar}$ (see discussion in WBGN06). The Pink Angel is a $\sim 2 \mathrm{~cm}$ diameter CAI that has a large pinkish interior (90\% of the total mass) surrounded by a whitish rim $(\sim 400 \mu \mathrm{m}$ wide). The interior is a powdery, porous aggregate of spinel $(60 \%$ by volume), sodalite (30\%), grossular $(5 \%)$, and some anorthite.
Sodalite occurs in dense patches (up to $50 \mu \mathrm{m}$ ) and often contains small spinel and grossular grains. The rim is a compact assemblage of spinel ( $40 \%$ ), anorthite ( $40 \%$ ), and diopside $(15 \%)$, where sodalite $(2 \%)$ appears interstitially between anorthite and diopside grains. In the thin section studied, two porphyritic olivine chondrules lie close to the Pink Angel (Fig. 1). The lower left chondrule also contains numerous sodalite grains, which occur interstitially between olivine grains. Sodalite does not appear in the lower right chondrule or in the local matrix. If sodalite formed within the Allende parent body by secondary processes, sodalite would also likely occur in both chondrules and the matrix. This observation strongly suggests that sodalite formed before the $\mathrm{CAI}$ and chondrule were accreted. Sodalite $\left(\mathrm{Na}_{8} \mathrm{Al}_{6} \mathrm{Si}_{6} \mathrm{O}_{24} \mathrm{Cl}_{2}\right)$ is rich in $\mathrm{Na}$ and $\mathrm{Cl}$. It is not a primitive high-temperature condensate but a late-formed volatile-rich alteration product (Hutcheon \& Newton 1981; Ikeda \& Kimura 1995).

Sulfur isotope compositions of sodalite and $\mathrm{Mg}$ isotope compositions of sodalite and anorthite were analyzed in situ within polished, C-coated thin sections with the CAMECA 6f ion microprobe at Arizona State University. Techniques used were similar 


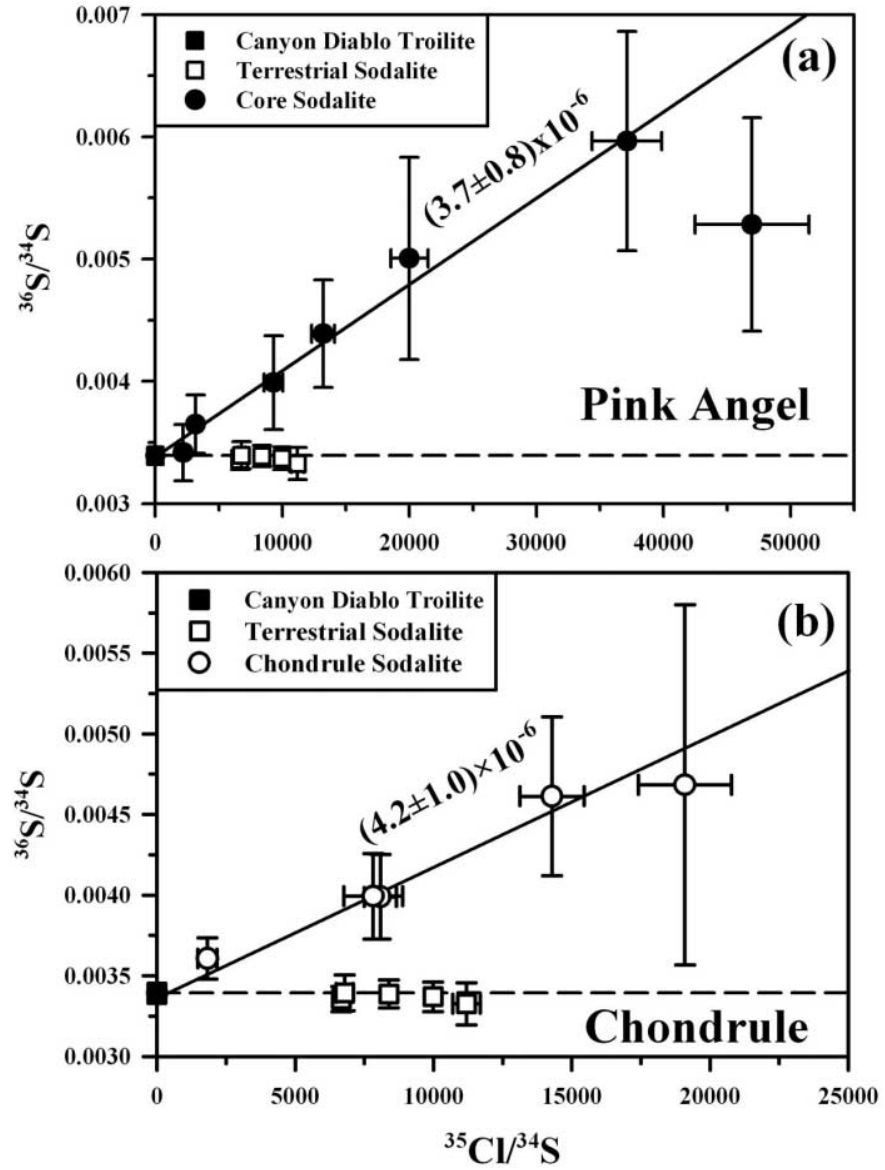

FIG. 2.-Correlation of ${ }^{36} \mathrm{~S} /{ }^{34} \mathrm{~S}$ with ${ }^{35} \mathrm{Cl} /{ }^{34} \mathrm{~S}$ in sodalite grains from $(a)$ the Pink Angel refractory inclusion and $(b)$ a nearby porphyritic olivine chondrule. One analysis was not included in the regression calculation for the isochron in panel $(a)$. The inferred ${ }^{36} \mathrm{Cl} /{ }^{35} \mathrm{Cl}$ ratios were calculated from the proportion of the decays of ${ }^{36} \mathrm{Cl}$ to ${ }^{36} \mathrm{~S}$. The ratios are essentially the same for the inclusion and the chondrule. Errors are $\pm 2 \sigma$. The horizontal dashed line is the normal ${ }^{36} \mathrm{~S} /{ }^{34} \mathrm{~S}$ ratio.

to those previously described (Lin et al. 2005). A mass resolving power of 4300 was used. The dynamic background was constant over the analysis period at a level of $\sim 0.009$ counts $\mathrm{s}^{-1}$. The secondary ion intensities were corrected for background and for counting system dead time. Canyon Diablo troilite and a terrestrial sodalite were used repeatedly as standards to check instrumental mass fractionation (IMF) and to verify that no ${ }^{36} \mathrm{~S}$ excess exists in these measurements. For both standards and sample, IMF was internally corrected by using ${ }^{33} \mathrm{~S} /{ }^{34} \mathrm{~S}$ according to a linear law. To determine the relative sensitivity factor of $\mathrm{Cl} / \mathrm{S}$, we used NBS-612 and NBS-610 glasses, which are reported to contain $\sim 16$ and 470 parts per million (ppm) S and $\mathrm{Cl}$, respectively. There is a serious need for better gravimetric standards of $\mathrm{S}$ and $\mathrm{Cl}$ at these low levels in an appropriate silicate matrix. A value of 0.83 was used in this study for the relative sensitivity of $\mathrm{Cl} / \mathrm{S}$.

\section{RESULTS}

Sodalite grains in the Pink Angel show clear ${ }^{36} \mathrm{~S}$ excesses (up to $760 \%$ ) that linearly correlate with ${ }^{35} \mathrm{Cl} /{ }^{34} \mathrm{~S}$ (Fig. $2 a$ and Table 1). The inferred ${ }^{36} \mathrm{Cl} /{ }^{35} \mathrm{Cl}$ ratio at the time of sodalite formation is $(3.7 \pm 0.8) \times 10^{-6}(2 \sigma)$. This is essentially the same as that previously observed in a Ningqiang CAI (Lin et al. 2004, 2005) and confirms those results. The relative sensitivity factor of $\mathrm{Cl} / \mathrm{S}$ (0.58) was used in Lin et al. (2005). If the sensitivity factor (0.83) determined on the NBS glasses is applied to their data, their in-
TABLE 1

Sulfur Isotopic Compositions of Sodalite in the Pink Angel AND THE CHONDRule

\begin{tabular}{|c|c|c|}
\hline Sample & ${ }^{35} \mathrm{Cl} /{ }^{34} \mathrm{~S}$ & $\begin{array}{l}{ }^{36} \mathrm{~S} /{ }^{34} \mathrm{~S} \\
\left(\times 10^{3}\right)\end{array}$ \\
\hline \multirow[t]{6}{*}{ Canyon Diablo troilite ....................... } & $<0.01$ & $3.396 \pm 0.008$ \\
\hline & $<0.01$ & $3.394 \pm 0.006$ \\
\hline & $<0.01$ & $3.399 \pm 0.007$ \\
\hline & $<0.01$ & $3.392 \pm 0.007$ \\
\hline & $<0.01$ & $3.396 \pm 0.007$ \\
\hline & $<0.01$ & $3.384 \pm 0.005$ \\
\hline \multirow[t]{5}{*}{ Terrestrial sodalite } & $11197 \pm 498$ & $3.33 \pm 0.13$ \\
\hline & $6669 \pm 66$ & $3.36 \pm 0.08$ \\
\hline & $9983 \pm 166$ & $3.37 \pm 0.09$ \\
\hline & $8392 \pm 146$ & $3.39 \pm 0.09$ \\
\hline & $6783 \pm 301$ & $3.39 \pm 0.11$ \\
\hline \multirow[t]{7}{*}{ 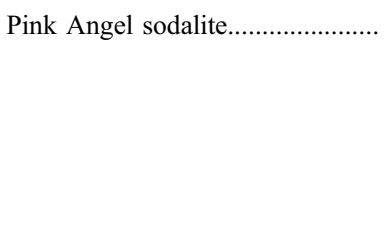 } & $9311 \pm 733$ & $3.99 \pm 0.39$ \\
\hline & $37125 \pm 2737$ & $5.97 \pm 0.90$ \\
\hline & $19997 \pm 1458$ & $5.01 \pm 0.83$ \\
\hline & $46969 \pm 4476$ & $5.28 \pm 0.87$ \\
\hline & $13220 \pm 907$ & $4.39 \pm 0.44$ \\
\hline & $3174 \pm 122$ & $3.65 \pm 0.24$ \\
\hline & $2204 \pm 44$ & $3.42 \pm 0.23$ \\
\hline \multirow{5}{*}{ 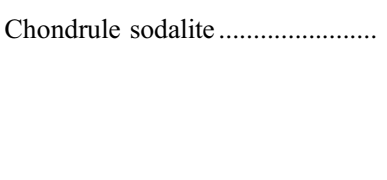 } & $14283 \pm 1165$ & $4.61 \pm 0.49$ \\
\hline & $19090 \pm 1690$ & $4.68 \pm 1.12$ \\
\hline & $8078 \pm 575$ & $3.99 \pm 0.26$ \\
\hline & $7819 \pm 1067$ & $3.99 \pm 0.27$ \\
\hline & $1827 \pm 349$ & $3.61 \pm 0.13$ \\
\hline
\end{tabular}

Note.-Errors are $\pm 2 \sigma$.

ferred ${ }^{36} \mathrm{Cl} /{ }^{35} \mathrm{Cl}$ ratio would be $\sim 3.7 \times 10^{-6}$. Sodalite grains in the porphyritic olivine chondrule reported here also exhibit large ${ }^{36} \mathrm{~S}$ excesses correlating with ${ }^{35} \mathrm{Cl} /{ }^{34} \mathrm{~S}$ (Fig. $2 b$ ). The inferred ${ }^{36} \mathrm{Cl} /{ }^{35} \mathrm{Cl}$ ratio is $(4.2 \pm 1.0) \times 10^{-6}$ for the sodalite in the chondrule, identical within errors to that in the Pink Angel. This suggests that the late alteration that produced the sodalite occurred at approximately the same time or the same site (possibly planetary) for both the Pink Angel and the chondrule.

Sodalite and anorthite within the core and rim of the Pink Angel show large variations of ${ }^{27} \mathrm{Al} /{ }^{24} \mathrm{Mg}$ (from 30 to 3300 ), but contain no resolvable ${ }^{26} \mathrm{Mg}$ excesses (Fig. 3), in agreement with previous data for the same inclusion (Villa et al. 1981). A few analyses of sodalite in the chondrule yield low $\mathrm{Al} / \mathrm{Mg}(<20)$ and

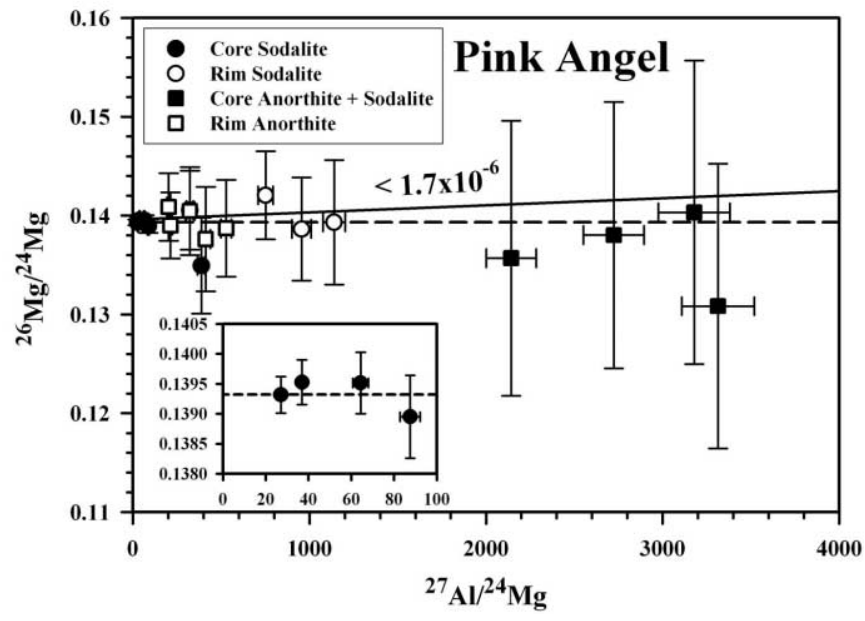

FIG. 3.- $\mathrm{Mg}$ isotopic compositions and $\mathrm{Al} / \mathrm{Mg}$ ratios of sodalite and anorthite in the Pink Angel. An upper limit for ${ }^{26} \mathrm{Al} /{ }^{27} \mathrm{Al}$ is $1.7 \times 10^{-6}$. Errors are $\pm 2 \sigma$. The horizontal dashed line refers to the normal ${ }^{26} \mathrm{Mg} /{ }^{24} \mathrm{Mg}$ ratio of 0.13932 . 


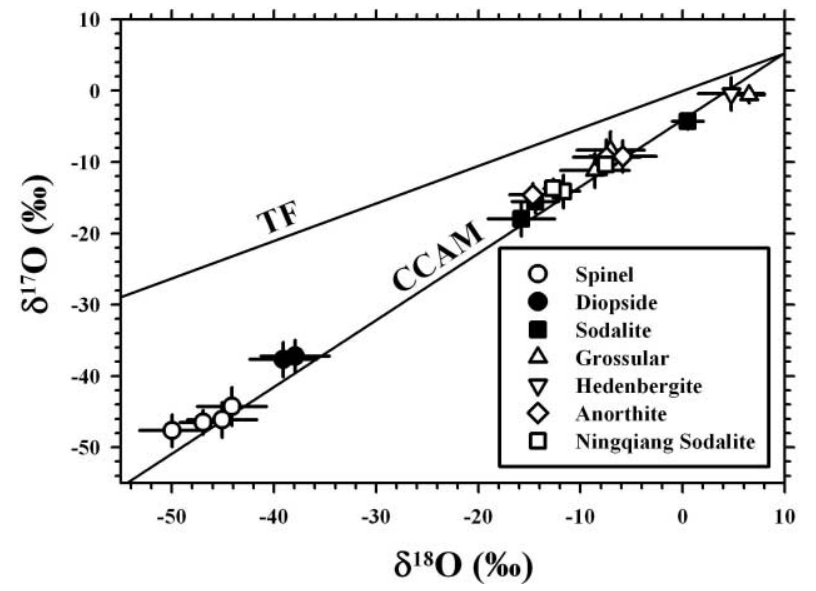

FIG. 4.-O isotope compositions of mineral phases in the Pink Angel. TF, terrestrial fractionation line; CCAM, carbonaceous chondrite anhydrous mineral line.

exhibit normal $\mathrm{Mg}$ isotopic compositions. An upper limit of ${ }^{26} \mathrm{Al} /{ }^{27} \mathrm{Al}$ for the Pink Angel is set at $1.7 \times 10^{-6}$. If we consider the canonical value of ${ }^{26} \mathrm{Al} /{ }^{27} \mathrm{Al}=5 \times 10^{-5}$ as the initial state, it implies that the time interval for the sodalite formation is $\geq 3.5 \mathrm{Myr}$. This is consistent with the conventional belief that the time interval is $\sim 2 \mathrm{Myr}$ between the formation of CAIs and chondrules (Huss et al. 2001).

The oxygen isotopes of individual minerals were measured. Spinel and diopside show typical ${ }^{16} \mathrm{O}$ enrichments with $\delta$ values of ${ }^{18} \mathrm{O}$ and of ${ }^{17} \mathrm{O}$ of approximately $-45 \%$, and the secondary phases, sodalite, anorthite, grossular, and hedenburgite, are relatively ${ }^{16} \mathrm{O}$ depleted. The data fall along the carbonaceous chondrite anhydrous mineral (CCAM) line in the three-O-isotope diagram (Fig. 4). The oxygen isotope compositions are compatible with extensive alteration of an original CAI with $\delta^{18} \mathrm{O}=$ $\delta^{17} \mathrm{O}=-50 \%$, where the relict phases are spinel and diopside. This points to an environment of alteration with "normal" planetary oxygen (terrestrial, bulk meteorites, Moon, or Mars), which may represent a nebular environment (Clayton \& Mayeda 1999). Whether this is the solar value is not known, as the solar oxygen ratios are not precisely known (cf. Hashizume \& Chaussidon 2005). This result on oxygen is typical of CAIs but represents far more extensive alteration. It appears that CAIs and chondrules interacted with halogen-rich material to form sodalite long after their original formation. This must have occurred in a common site for both the precursor to the Pink Angel and the chondrule before they accreted into the Allende planetary body. The sources of halogens and $\mathrm{Na}$ and the mechanisms of alteration remain to be identified. The evidence for alteration in a volatile-rich environment is based on the high $\mathrm{Na}, \mathrm{Cl}$, and I contents of this inclusion. As yet, no clear evidence of aqueous alteration products has been found. If the apparent absence of water is correct, this must provide a clue to the alteration process.

\section{DISCUSSION}

These data show that halogen-rich phases in the Pink Angel and the chondrule contain large ${ }^{36} \mathrm{~S}$ excesses that correlate well with the chlorine concentration and strongly support the argument for in situ decay of ${ }^{36} \mathrm{Cl}$. However, these phases are devoid of any significant ${ }^{26} \mathrm{Mg}$ excesses from the decay of ${ }^{26} \mathrm{Al}$ (Hutcheon \& Newton 1981; Villa et al. 1981; Lin et al. 2005; this work). We further note that the Pink Angel contains essentially pure radiogenic ${ }^{129} \mathrm{Xe}$ from the decay of short-lived ${ }^{129} \mathrm{I}(\bar{\tau}=23 \mathrm{Myr})$ with ${ }^{129} \mathrm{I} /{ }^{127} \mathrm{I} \sim 1 \times 10^{-4}$ (Villa et al. 1981; Swindle et al. 1988). For this inclusion, Swindle et al. (1988) found that the I-Xe system was altered by a nonnebular secondary process. This inclusion does not have any significant amount of ${ }^{36} \mathrm{Ar}$ excess, which is the principal decay branch of ${ }^{36} \mathrm{Cl}$ ( Villa et al. 1981). The cosmogenic ${ }^{36} \mathrm{Ar}$ concentration is very low in the same inclusion $\left[{ }^{36} \mathrm{Ar} /{ }^{35} \mathrm{Cl}=\right.$ $\left.(2-12) \times 10^{-9}\right]$, as is the cosmic-ray-induced ${ }^{128} \mathrm{Xe}$ (Villa et al. 1981). The large ${ }^{36} \mathrm{~S}$ excesses in the Pink Angel and the chondrule cannot result from late cosmic-ray production in the solar system.

We must reconcile these obviously discrepant results along with the absence of ${ }^{26} \mathrm{Al}$. The ${ }^{36} \mathrm{Ar}$ produced by the decay of ${ }^{36} \mathrm{Cl}$ must have been almost completely lost after the formation of the sodalite. This must also have occurred without any major ${ }^{129} \mathrm{Xe}$ loss from the same phase. In discussing this matter, it is important to consider the structure of sodalite. The sodalite family has an open aluminosilicate framework structure closely related to the zeolites. Sulfur is bound in the sodalite crystal structure where $\left[\mathrm{SO}_{4}\right]^{2-}$ substitutes for two $\mathrm{Cl}^{-}$to form solid solutions of $\left(\mathrm{SO}_{4}^{2-}\right.$, $\mathrm{Cl}^{-}$)-sodalite-nosean with a large miscibility gap (Kotel'nikov et al. 2005). Assuming that ${ }^{36} \mathrm{Cl}$ was the source of the ${ }^{36} \mathrm{~S}$ excesses, to interpret the observations concerning ${ }^{36} \mathrm{Ar}$ and ${ }^{129} \mathrm{Xe}$ we must infer that there was extensive diffusive gas loss of ${ }^{36} \mathrm{Ar}$ (presumably due to an episode of heating) that occurred after the sodalite formed and that the duration of this process was not much longer than 3-5 Myr. As $\bar{\tau}^{129} \mathrm{I}=23 \mathrm{Myr}$, there would not be much loss of ${ }^{129} \mathrm{Xe}$. The ${ }^{129} \mathrm{Xe}$ disturbance inferred by Swindle et al. (1988) may be due to longer term diffusion or late metamorphism that would also cause Ar loss. With regard to sulfur, it is structurally bound, so the possibility of diffusive loss would arguably have been small. Diffusion of noble gases from the sodalite open structure is to be expected. The diffusive loss mechanisms in sodalite for Ar, Xe, and S should now be measured in laboratory experiments to test this hypothesis. We note that a thermoluminescence study revealed that the Pink Angel experienced a low-temperature $\left(<200^{\circ} \mathrm{C}\right)$ metamorphism on its parent body (Guimon et al. 1995). If this were the only disturbance, it would place severe constraints on the model outlined above.

We are then left with the issue of what the ${ }^{36} \mathrm{Cl}$ inventory was at the time when ${ }^{26} \mathrm{Al}$ was present. If the ${ }^{36} \mathrm{Cl}$ is decoupled from ${ }^{26} \mathrm{Al}$, then this requires a mechanism that produces abundant ${ }^{36} \mathrm{Cl}$ and negligible ${ }^{26} \mathrm{Al}$. If the time interval for the sodalite formation is $\sim 3.5 \mathrm{Myr}$ and the observed ratio represents the residue of a much higher ${ }^{36} \mathrm{Cl}$ inventory coupled with ${ }^{26} \mathrm{Al}$ production, then it would require a source that is capable of producing ${ }^{36} \mathrm{Cl} /{ }^{35} \mathrm{Cl} \sim$ $10^{-2}$ and that would presumably also have to be responsible for a substantial fraction of the ${ }^{26} \mathrm{Al}$. In both of these considerations, we conclude that no stellar nucleosynthetic source can be responsible for the ${ }^{36} \mathrm{Cl}$ inventory, even at the level of $10^{-4}$ (Busso et al. 1999; WBGN06). A SN source would only give ${ }^{36} \mathrm{Cl} /{ }^{35} \mathrm{Cl} \sim$ $10^{-6}$, and an AGB source would give ${ }^{36} \mathrm{Cl} /{ }^{35} \mathrm{Cl}=4.7 \times 10^{-7}$, correlating with ${ }^{26} \mathrm{Al}$ (Busso et al. 1999; WBGN06). Accounting for the canonical ${ }^{26} \mathrm{Al} /{ }^{27} \mathrm{Al}$ from a SN II source would give extremely high ${ }^{53} \mathrm{Mn}$ and ${ }^{60} \mathrm{Fe}$ in the ESS, which are not observed (Busso et al. 1999, 2003; WBGN06). The high ${ }^{36} \mathrm{Cl}$ would exacerbate this situation, as a SN II source that might have provided the ${ }^{26} \mathrm{Al}$ would only provide ${ }^{36} \mathrm{Cl} /{ }^{35} \mathrm{Cl} \sim 10^{-6}$ in this case (WBGN06). We conclude that the ${ }^{36} \mathrm{Cl}$ case is similar to that for ${ }^{10} \mathrm{Be}$ discovered by McKeegan et al. (2000). The ${ }^{10} \mathrm{Be}$ can only be explained by spallation reactions. ${ }^{36} \mathrm{Cl}$ can be produced abundantly in particle bombardment by an active early Sun (Goswami et al. 2001; Leya et al. 2003). The basic question remains as to whether the models of particle bombardment can adequately explain several nuclei, including ${ }^{26} \mathrm{Al}$. If not, then we would infer that there was an initial ${ }^{26} \mathrm{Al}$ inventory from a stellar source and that a later episode of bombardment by the early Sun produced 
${ }^{10} \mathrm{Be}$ and ${ }^{36} \mathrm{Cl}$ but did not affect the global inventory of ${ }^{26} \mathrm{Al}$. It is not evident that the solar energetic particle (SEP) irradiation responsible for the ${ }^{10} \mathrm{Be}$ would be responsible for the ${ }^{36} \mathrm{Cl}$ production. We note that from all data currently available on ${ }^{10} \mathrm{Be}$, there are some clear cases in which this nuclide was present and ${ }^{26} \mathrm{Al}$ was absent. There are also cases in which both are present. The relationship between ${ }^{36} \mathrm{Cl}$ and ${ }^{10} \mathrm{Be}$ has not been established. In the case of ${ }^{36} \mathrm{Cl}$, the chemical source for the late alteration requires careful consideration. Storing volatiles inside a planetesimal that contains a short-lived nuclide like ${ }^{36} \mathrm{Cl}$ that is here attributed to an irradiation cannot immediately be explained.

Several irradiation scenarios have been proposed for the simultaneous production of short-lived nuclides. These include irradiation in the interstellar medium by Galactic cosmic rays (Desch et al. 2004) and SEP spallation reactions very close to an active proto-Sun (Shu et al. 1997, 2001; McKeegan et al. 2000; Leya et al. 2003) or at a meteorite-forming region (Goswami et al. 2001). Irradiation of solar material close to a proto-Sun would yield an initial ${ }^{36} \mathrm{Cl} /{ }^{35} \mathrm{Cl}=1.3 \times 10^{-4}$ and ${ }^{26} \mathrm{Al} /{ }^{27} \mathrm{Al}=1.2 \times$ $10^{-5}$ for the case without saturation and ${ }^{36} \mathrm{Cl} /{ }^{35} \mathrm{Cl}=4.8 \times 10^{-5}$ and ${ }^{26} \mathrm{Al} /{ }^{27} \mathrm{Al}=1.0 \times 10^{-5}$ for the case with a long-term irradiation (1 Myr; Leya et al. 2003). Irradiation of nebular material by SEPs at the asteroidal distance could also produce a sufficient amount of ${ }^{36} \mathrm{Cl}$ close to the measured data, but there is a considerable shortfall in ${ }^{26} \mathrm{Al}$ production (Goswami et al. 2001). This is in accord with the absence of ${ }^{26} \mathrm{Al}$ in the sodalite with abundant ${ }^{36} \mathrm{Cl}$. It is therefore plausible to attribute the source of ${ }^{36} \mathrm{Cl}$ to a local irradiation, but the theoretical treatment of an irradiation model must be reconsidered seriously to account for the level of ${ }^{36} \mathrm{Cl}$ observed in alteration products for CAIs and chondrules. The mechanism of formation of such alteration products must be resolved with proper consideration of the circumstances in which the volatile elements like $\mathrm{Cl}$ are both formed and stored.

In conclusion, we provide strong evidence in support of the existence of ${ }^{36} \mathrm{Cl}$ in CAIs, as observed by Lin et al. (2005), but also in chondrules as well. ${ }^{36} \mathrm{Cl}$ is not correlated with ${ }^{26} \mathrm{Al}$. These results on ${ }^{36} \mathrm{Cl}$ indicate that intense late irradiation processes occurred in the ESS, as proposed by WBGN06 based on the data of Lin et al. (2005). The particle fluence required to provide the ${ }^{10} \mathrm{Be}$ appears to be commensurate with that needed to produce the observed ${ }^{36} \mathrm{Cl}$ abundances, and such a fluence is also sufficient to make other short-lived nuclides, ${ }^{41} \mathrm{Ca}$ and possibly some ${ }^{53} \mathrm{Mn}$, but not enough for the ${ }^{26} \mathrm{Al}$ found in meteorites (Goswami et al. 2001; Leya et al. 2003).

This work was supported by Chinese National Natural Science Foundation for Distinguished Young Scholars (grant 40325009), by the "One-Hundred-Talent Program" of the Chinese Academy of Sciences, by the Minor Planet Foundation of China, by DOE grant DE-FG-03-88ER13851 (G. J. W.), and by a NASA grant NNG 05GH3736 (L. A. L./Y. G.). The terrestrial sodalite sample used in this study was prepared by Xin Hua. The authors wish to thank M. Busso for a detailed constructive and critical review. This is Caltech Division of Geological and Planetary Science Contribution 9133(1121).

\section{REFERENCES}

Armstrong, J. T., \& Wasserburg, G. J. 1981, Lunar Planet. Sci. Conf., 12, 25

Busso, M., Gallino, R., \& Wasserburg, G. J. 1999, ARA\&A, 37, 239 2003, Publ. Astron. Soc. Australia, 20, 356

Cameron, A. G. W., Höflich, P., Myers, P. C., \& Clayton, D. D. 1995, ApJ, 447, L53

Clayton, R. N., \& Mayeda, T. K. 1999, Geochim. Cosmochim. Acta, 63, 2089 Desch, S. J., Connolly, H. C., Jr., \& Srinivasan, G. 2004, ApJ, 602, 528

Endt, P. M. 1990, Nucl. Phys. A, 521, 1

Feigelson, E. D., Garmire, G. D., \& Pravdo, S. H. 2002, ApJ, 572, 335

Goswami, J. N., Marhas, K. K., \& Sahijpal, S. 2001, ApJ, 549, 1151

Guimon, R. K., Symes, S. J. K., Sears, D. W. G., \& Benoit, P. H. 1995, Meteoritics, 30, 704

Hashizume, K., \& Chaussidon, M. 2005, Nature, 434, 619

Huss, G. R., MacPherson, G. J., Russell, S. S., Srinivasan, G., \& Wasserburg, G. J. 2001, Meteoritics Planet. Sci., 36, 975

Hutcheon, I. D., \& Newton, R. C. 1981, Lunar Planet. Sci. Conf., 12, 491

Ikeda, Y., \& Kimura, M. 1995, in Proc. 19th Symp. Antarctic Meteorites, ed. K. Yanai (Tokyo: NIPR), 97

Jordan, J., \& Pernicka, E. 1981, Meteoritics, 16, 332

Kotel'nikov, A. R., Koval'skii, A. M., \& Suk, N. I. 2005, Geochem. Int., 43, 544

Leya, I., Halliday, A. N., \& Wieler, R. 2003, ApJ, 594, 605
Lin, Y., Guan, Y., Leshin, L. A., Ouyang, Z., \& Wang, D. 2004, Lunar Planet. Sci. Conf., 35, 2084

. 2005, Proc. Natl. Acad. Sci., 102, 1306

McKeegan, K. D., Chaussidon, M., \& Robert, F. 2000, Science, 289, 1334

McKeegan, K. D., \& Davis, A. M. 2003, in Treatise on Geochemistry, Vol. 1, ed.

H. D. Holland, K. K. Turekian, \& A. M. Davis (Amsterdam: Elsevier), 431

Murty, S. V. S., Goswami, J. N., \& Shukolyukov, Yu. A. 1997, ApJ, 475, L65

Murty, S. V. S., \& Wasserburg, G. J. 1996, Meteoritics Planet. Sci., 31, A94

Rai, V. K., Murty, S. V. S., \& Ott, U. 2003, Geochim. Cosmochim. Acta, 67, 4435

Sahijpal, S., Goswami, J. N., Davis, A. M., Grossman, L., \& Lewis, R. S. 1998, Nature, 391, 559

Shu, F. H., Shang, H., Glassgold, A. E., \& Lee, T. 1997, Science, 277, 1475

Shu, F. H., Shang, H., Gounelle, M., Glassgold, A. E., \& Lee, T. 2001, ApJ, 548,1029

Swindle, T. D., Caffee, M. W., \& Hohenberg, C. M. 1988, Geochim. Cosmochim. Acta, 52, 2215

Villa, I. M., Huneke, J. C., Papanastassiou, D. A., \& Wasserburg, G. J. 1981, Lunar Planet. Sci. Conf., 12, 1115

Wasserburg, G. J., Busso, M., Gallino, R., \& Nollett, K. M. 2006, Nucl. Phys. A, in press (WBGN06)

Wasserburg, G. J., Busso, M., Gallino, R., \& Raiteri, C. M. 1994, ApJ, 424, 412 